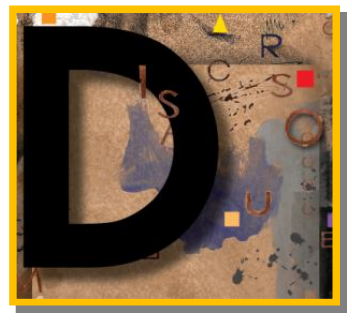

DISCURSOS CONTEMPORÂNEOS EM

ESTUDO

ISSN 2237-7247

\section{PERCURSOS E AVANÇOS DO TEXTO MULTIMODAL: NOVAS PERSPECTIVAS NA CONTEMPORANEIDADE}

\author{
Josenia Antunes Vieira $(\mathrm{UnB})$
} Janaína de Aquino Ferraz (UnB) ${ }^{2}$

No âmbito das novas perspectivas contemporâneas para o texto, a comunicação sempre foi multimodal. Tal premissa torna possível determinar os percursos do fenômeno da multimodalidade nas práticas sociais do contexto atual. Assim, à luz dos preceitos da Semiótica Social - que defende serem os participantes em posição de poder os que levam os outros participantes a um maior esforço de interpretação -, com enfoque nas diversas semioses envolvidas na produção de sentidos como um meio legítimo de método analítico, pôde-se observar que, independentemente do tipo de discurso a ser estudado, é necessário considerá-lo frente ao contexto social e cultural, tendo em vista ser o discurso um modo de ação capaz de alterar o mundo e os indivíduos que dele participam. Nesse sentido, os textos aqui analisados revelaram aspectos ideológicos da construção multimodal e o interesse dos produtores de textos guiados pelas necessidades sociais. Em vista disso, conclui-se que devemos nos voltar para formas de investigação de textos multimodais, desconstruindo a ação alienadora da imagem e construindo uma avaliação crítica de tudo o que vemos. Aprender a lidar com o excesso de informações do mundo mediado das sociedades modernas é portentoso recurso de pesquisa e de construção de conhecimento, desvelando os fenômenos da linguagem e instrumentalizando para um mundo multimodal, povoado de imagens e de sons, para saber lidar criticamente com a natureza desse tipo de discurso.

Palavras-chave: Análise do Discurso. Multimodalidade.

Under the new contemporary perspectives to the text, the communication has always been multimodal. This assumption makes it possible to determine the pathways of the phenomenon of social practices of multimodality in the present context. In the light of the precepts of Social Semiotics - defending that the participants in a more powerful position lead other participants to a greater degree of interpretation -, with focus on various semiosis involved in the production of meaning as a legitimate means of analytical method, it was observed that regardless of the type of discourse to be studied, it is necessary to consider it in the social and cultural context in order to be a speech a mode of action capable to change the world and the individuals who participate in it. In this sense, the texts reviewed here reveal the ideological aspects of construction and the interest of producers of multimodal texts guided by social needs. Accordingly, we conclude that we must turn to research multimodal texts, deconstructing the alienating action of image and building a critical evaluation of what we see. Learning to deal with overload of information of the world of modern societies is a powerfull resource for research and knowledge building, revealing the phenomena of language and equipping for a multimodal world, filled with images and sounds in order to learn to deal critically with nature of this type of discourse.

Keywords: Discourse Analysis. Multimodality.

\footnotetext{
${ }^{1}$ Pós-doutora em Análise de Discurso Crítica (CNPq, 2001), pela Universidade Clássica de Lisboa. Professora do Programa de Pós-Graduação em Linguística (PPGL) da Universidade Brasília (UnB). E-mail: josenia.unb@gmail.com.

${ }^{2}$ Doutora em Linguística (UnB); professora do Departamento de Linguística, Português e Línguas Clássicas da Universidade de Brasília. E-mail: ferraz.jana@gmail.com.
} 


\section{Introdução}

Este artigo tem como propósito discutir algumas das novas perspectivas contemporâneas para o texto multimodal. A afirmação de Kress (2000) sobre a comunicação sempre ter sido multimodal é por nós assumida como premissa para determinar os percursos do fenômeno da multimodalidade como ligada às práticas sociais do contexto atual. Acreditamos que, partindo desse ponto inicial, podemos delinear com mais clareza quais as implicações para a expressão de significados que nos circundam. Assim, propomo-nos a fazer uma reflexão acerca do verdadeiro papel de semioses outras que não somente a escrita, eternamente celebrada nas sociedades complexas, a fim de demonstrar que, independentemente do tipo de discurso a ser estudado, é necessário considerá-lo frente ao contexto social e cultural, tendo em vista ser o discurso um modo de ação capaz de alterar o mundo e os indivíduos que dele participam (FAIRCLOUGH, 2001).

Não pretendemos focar nossos esforços na discutida dicotomia do "verbal e do não verbal", mas, sim, dirigir nosso olhar sobre como os sentidos são construídos por meio da utilização simultânea de várias modalidades. Tomando o que dizem Baldry e Thibault (2006, p. 18) sobre os textos multimodais serem "produtos compostos de efeitos combinatórios de todas as fontes usadas para criá-los e interpretá-los", consideramos o conhecimento sobre efeitos e reflexos do contato entre diferentes recursos semióticos como crucial para o entendimento dos sentidos construídos nos textos, bem como para a sistematização da pesquisa no âmbito dos estudos multimodais brasileiros.

A inserção de tais conceitos na Semiótica Social para contextualizar o discurso visual imagem (mais especificamente) - e os recursos semióticos utilizados na sua produção, como auxiliares na forma de interpretação e de significação desses discursos, aponta para a análise do gênero multimodal, ao mesmo tempo em que explica como a multimodalidade impera nos dias atuais, em que imagem e palavra aproximam-se cada vez mais devido aos avanços tecnológicos. Dessa forma, entendemos ser a multimodalidade uma grande aliada à interpretação dos sentidos do texto e, portanto, objeto relevante para uma discussão amadurecida na pesquisa de natureza qualitativa, uma análise interpretativista, levada a efeito neste artigo. 


\section{A Semiótica Social}

Com vistas a direcionar nossa discussão sobre o texto multimodal, optamos, neste primeiro momento, por rever brevemente a história sobre a Semiótica, campo de estudos há muito explorado por diversas áreas da ciência. Nessa perspectiva, retomamos três propostas que deixaram seu legado expansionista para o campo dos estudos linguísticos, antes do surgimento da Teoria Multimodal (KRESS; VAN LEEUWEN, 2001) que passou a incluir como objeto de estudo outros modos comunicacionais além da linguagem verbal. Para melhor compreensão dessas três escolas, elaboramos a representação visual sobre essas diferentes perspectivas.

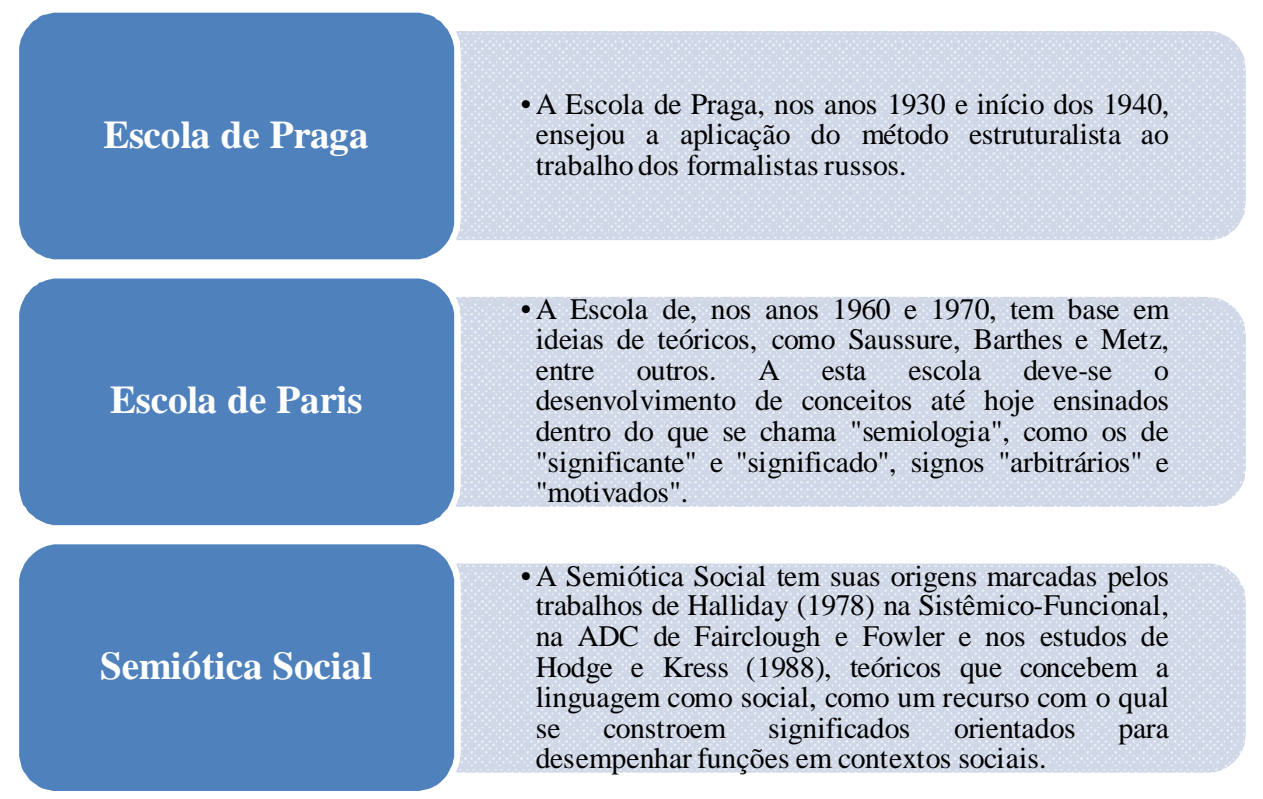

Figura 1 - Abordagens Semióticas.

Um dos estudos considerados base no campo da Semiótica Social é o realizado por Hodge e Kress (1988) que, ao levar em conta modos semióticos além da linguagem verbal, abre caminho a trabalhos como o de Kress e van Leeuwen (1996). Hodge e Kress (1988) propõem uma reconstrução da semiótica tradicional com base em críticas sobre o fato de esta negligenciar as funções e os usos sociais dos sistemas semióticos pelos produtores dos signos. Assim, uma das premissas da abordagem semiótica proposta é o reconhecimento de que, para se compreender os processos e as estruturas da linguagem, é indispensável levar-se em conta sua dimensão social e considerá-la ponto de partida para a análise dos sistemas de significado. Nesse sentido, verificamos, com facilidade, a influência da obra de Halliday no que tange a seus ensinamentos 
sobre as funções sociais da linguagem. Além dessa premissa, outra que orienta a Semiótica Social é o estudo norteado pela abordagem de modos semióticos que vai além da linguagem verbal e que não a considera mais considerando uma modalidade em isolada.

Desse modo, Hodge e Kress (1988, p. 261) definem a semiótica como "o estudo geral da semiose, isto é, dos processos e dos efeitos de produção e de reprodução, de recepção e de circulação de significado em todas as formas, usadas por todos os tipos de agentes de comunicação”. A Semiótica Social, portanto, dedica-se ao estudo da semiose humana, realizada em qualquer sistema semiótico, "como um fenômeno inerentemente social em suas fontes, funções, contextos e efeitos" (HODGE; KRESS, 1988, p. 261).

Nessa perspectiva social da produção e da recepção dos significados e do reconhecimento da importância do modo semiótico visual na comunicação em sociedade - a qual vem, cada vez mais, produzindo textos multimodais, textos produzidos com base em mais de um modo representacional e comunicacional -, é desenvolvida a gramática do design visual (KRESS; VAN LEEUWEN, 2006). Tal gramática, orientada para o estudo da comunicação visual nas culturas ocidentais, vem como uma resposta à demanda por métodos de análise textual que contemplem a linguagem visual como modo semiótico, de maneira a abrir possibilidades concretas e sistemáticas de descrição de todos os significados veiculados textualmente.

Assim, a proposta corresponde, de fato, à mudança no "cenário semiótico" nas últimas décadas, no sentido de valorizar o visual como modo de comunicação. Essa postura abala a hegemonia absoluta antes conferida ao texto escrito, à linguagem verbal (KRESS; LEITEGARCÍA; VAN LEEUWEN, 1997). Tem início, portanto, a corrente de estudos à qual Jewitt e Oyama (2001) se referem como "semiótica social da comunicação visual", cujos trabalhos têm como obra norteadora a gramática do design visual, tema de nossa próxima seção.

\section{A gramática do design visual: a sintaxe visual em foco}

O termo "gramática", devido ao seu uso tradicional traz, consigo, a ideia de um conjunto de regras (KRESS; VAN LEEUWEN, 1996). No entanto, na gramática do design visual, esse termo ganha novo direcionamento, sinalizando o propósito de enfoque na forma como se dá a combinação de pessoas, de lugares e de coisas em um todo significativo. Nas palavras de Kress, Leite-García e van Leeuwen (1997, p. 259), a ênfase recai sobre a análise da "sintaxe visual", e não no seu "léxico", como o fazem outras abordagens da Semiótica. O objetivo é compilar "as principais estruturas composicionais que têm se tornado convenções ao longo da história da semiótica visual e analisar como elas são usadas pelos produtores de imagem contemporâneos para produzir sentido" (KRESS; VAN LEEUWEN, 1996, p. 1). 
Desse modo, uma abordagem semiótica social da comunicação visual, segundo Jewitt e Oyama (2001, p. 134), abrange "a descrição dos recursos semióticos, o que pode ser dito e feito com imagens (e outros meios visuais de comunicação), além de como as coisas que as pessoas dizem e fazem com imagens podem ser interpretadas". De acordo com esse estudo, os semioticistas sociais podem ajudar também na expansão dos recursos semióticos, fornecendo novos ou possibilitando novas formas de uso dos já existentes, gerando mais ferramentas para a produção e para a interpretação da comunicação visual.

É importante ressaltar outro diferencial da gramática do design visual em relação a outras gramáticas: a rejeição do estudo das formas gramaticais de maneira desvinculada do significado. $\mathrm{Na}$ gramática do design visual, tais formas são concebidas como "recursos para codificar interpretações da experiência e formas de (inter)ação social" (KRESS; VAN LEEUWEN, 1996, p. 1). Essa concepção funcional se baseia nas ideias de Halliday $(1978,1985$, 1994), formuladas originalmente para a linguagem verbal. Em consonância com essa ideia, propomos uma figura para visualizarmos o foco dos estudos semióticos sociais, particularmente na comunicação visual que se volta para a sintaxe visual.

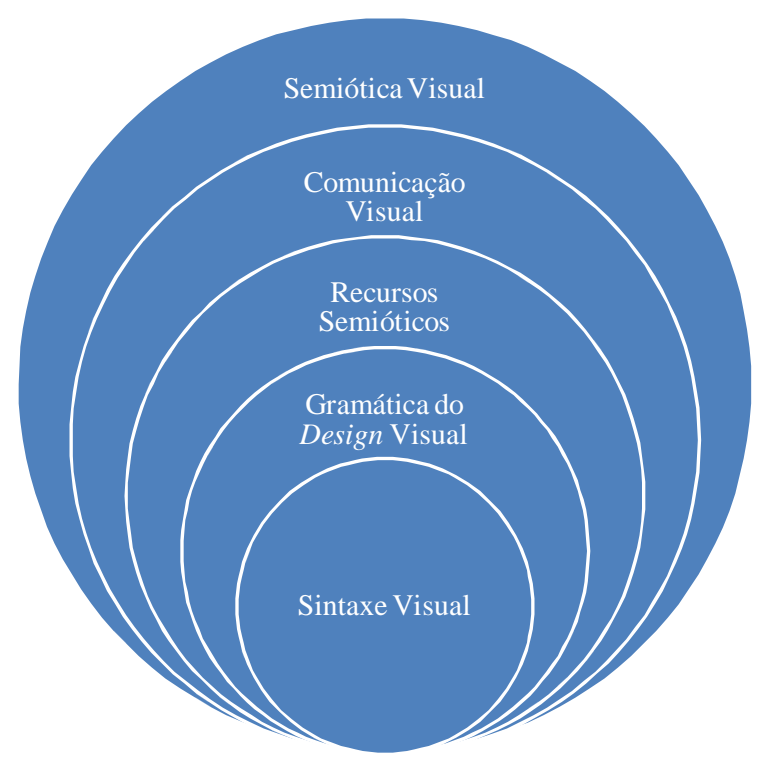

Figura 2 - O enfoque da sintaxe visual na proposta da Semiótica Social

O propósito da gramática do design visual é focalizar o processo de produção sígnica, compreendido como uma ação social realizada em determinado uso e contexto, em que o interesse do produtor do signo determina a forma de representação. Esse produtor expressa o significado pretendido por meio do modo semiótico que disponibiliza a forma mais apropriada, o 
significante, e esse processo conduz a signos motivados. Nesse ínterim, no processo de produção do signo, os estratos significante e significado podem ser tratados como relativamente independentes um do outro (KRESS; VAN LEEUWEN, 1996). Esse aspecto determina outra diferença entre a Semiótica Social e outras escolas de Semiótica, como a de Paris, uma vez que, ao contrário desta, aquela defende que a relação entre significante e significado não é arbitrária, mas socialmente motivada e, portanto, permeada por questões ideológicas. Para ilustrarmos melhor essa diferença, observemos os exemplos seguintes de signos, de acordo com cada uma das escolas:

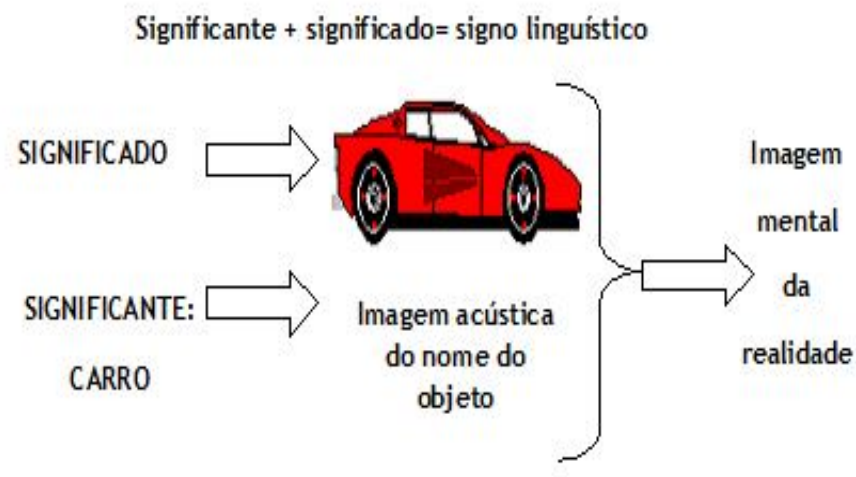

Fonte: elaboração nossa

Figura 3 - Signo na concepção saussureana (Escola de Paris)

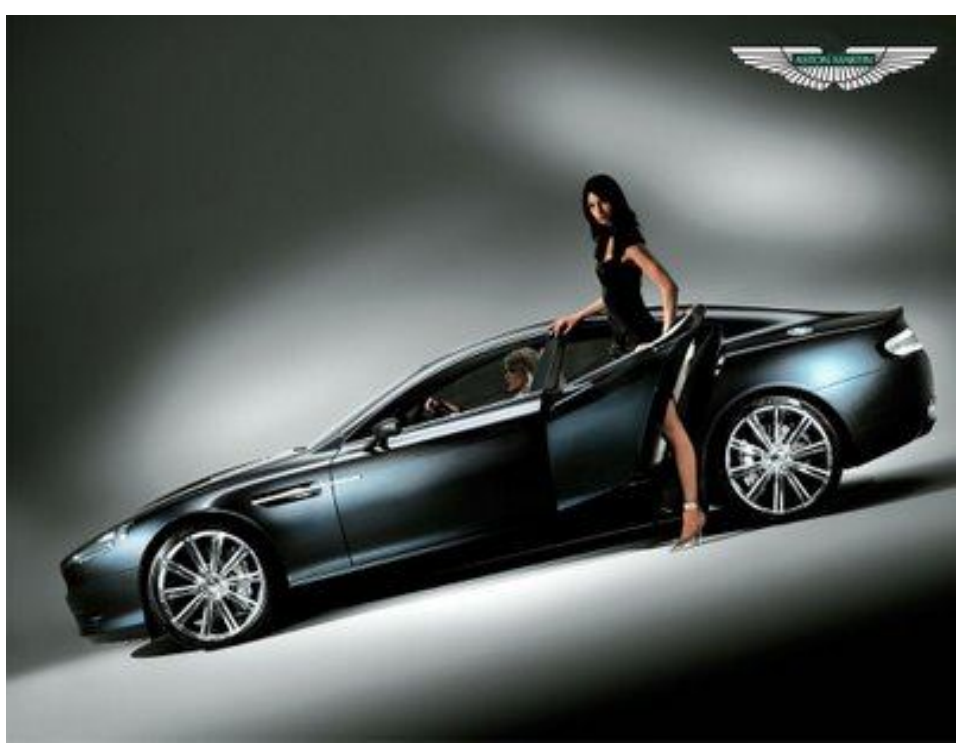

Figura 4 - Representação de carro de acordo com a ideologia do produtor de signos

Diferentemente do que propõe Saussure, a representação do signo "carro", na Figura 4, não é necessariamente arbitrária, pois pode receber influências dos produtores de signos. De acordo com a Semiótica Social, os produtores sempre procuram as formas mais plausíveis para 
representar o que acreditam ser mais adequado em determinado contexto. Isso é bem ilustrado com a composição da ideia de carro luxuoso, atrelada à figura da mulher elegante e sofisticada, representando o sucesso que esse objeto do mundo real possui na sociedade pós-moderna, o que torna a relação entre significante e significado socialmente motivada.

Assim, a questão do social é central, uma premissa da gramática do design visual, que considera "todas as formas de produção de sentido como uma atividade social, situada no campo da política, nas estruturas de poder, e, desse modo, sujeita a contestações oriundas de diferentes interesses dos produtores de textos" (KRESS; LEITE-GARCÍA; VAN LEEUWEN, 1997, p. 259). É assim que Kress e van Leeuwen (1996) partem de uma base social para uma abordagem fundada na comunicação, pois consideram que os significados, independentemente do modo semiótico com que são construídos, carregam uma natureza social, relacionada aos interesses de seus produtores e, portanto, com suas ideologias e com as questões de poder atreladas a tais significados. Consequentemente, "as mensagens produzidas pelos indivíduos refletirão as diferenças, as incongruências e os embates que caracterizam a vida social" (KRESS; VAN LEEUWEN, 1996, p. 18).

Além desse, outro ponto em que a Semiótica Social difere da Semiótica Estruturalista da Escola de Paris é quanto ao uso do termo "recurso" tratado, nesta última, como "código". Os sistemas semióticos foram considerados códigos: "conjuntos de regras para conectar signos e significados" (JEWITT; OYAMA, 2001, p. 134). Argumentam, a esse respeito, Jewitt e Oyama (2001) dizendo que, atualmente, apenas algumas formas de comunicação visual, como o código de trânsito, funcionam à base de prescrições estritas; outras, como desenhos infantis, baseiam-se em criatividade, em convenções e em exemplos, pois, nesses desenhos, não operam tais códigos. De acordo com Jewitt e Oyama (2001), o mesmo ocorre com a interpretação das imagens: há quem siga regras de interpretação e há quem crie suas próprias de interpretações e de conexões intertextuais. Desse modo, têm-se, em diferentes contextos, diferentes tipos de "regras" para o uso dos recursos visuais na produção e na interpretação. Vejamos isso nos seguintes exemplos:

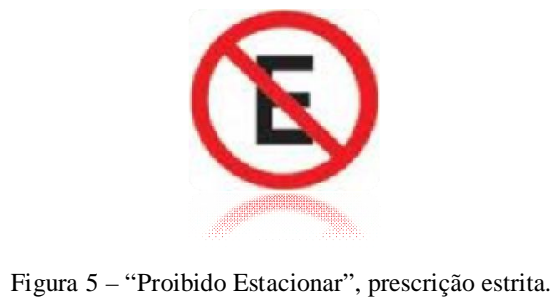



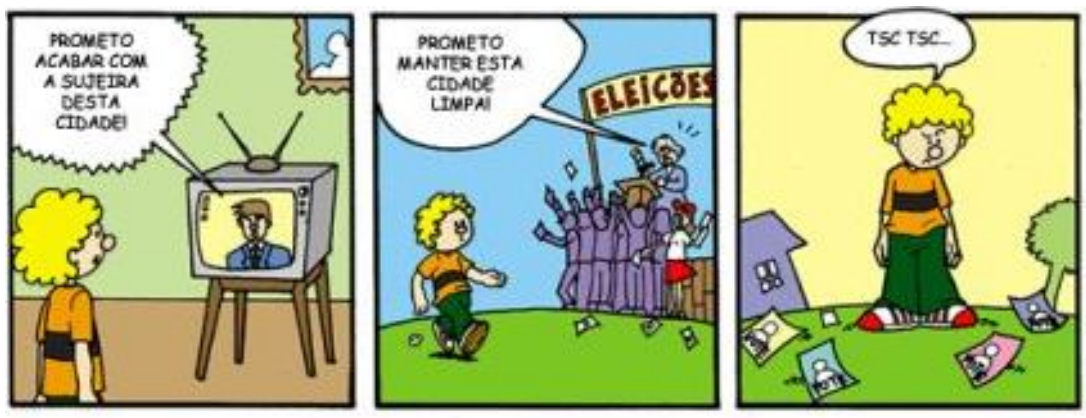

Fonte: 〈http://ideiasonline.wordpress.com>

Figura 6 - Representação de campanha política

O percurso gerativo de sentido nos dois exemplos ilustra bem as diferentes perspectivas de representação dos significados; no primeiro, no sinal de trânsito, o significado é prescrito, não há negociação; já no segundo, na tirinha de humor, o autor utiliza-se de conexões intertextuais que levam o leitor a focar no discurso praticado por políticos em campanha. Na tirinha, as convenções sociais são discutidas, já que a fala do político em campanha difere de suas ações, convidando o leitor deste texto a refletir sobre a prática social em questão.

Os recursos semióticos, conforme Jewitt e Oyama (2001), possuem um significado potencial, ou seja, um conjunto limitado de significados prováveis a serem ativados pelos produtores e observadores das imagens em determinado contexto social. Um aspecto central enfatizado pela abordagem Semiótica Social diz respeito à natureza dos recursos semióticos: eles são "produtos de histórias culturais e de recursos cognitivos que usamos para criar significados na produção e na interpretação de mensagens visuais e de outros tipos" (JEWITT; OYAMA, 2001, p. 136). Na gramática do design visual, os significados potenciais desses recursos são mapeados em redes de sistemas (System Networks) - forma de diagramação também derivada do trabalho de Halliday. Tais redes fornecem as ferramentas para a descrição das práticas de produção de signos. Jewitt e Oyama (2001) enfatizam, ainda, a natureza simbólica das representações e das relações promovidas pelos recursos semióticos: elas não são reais e é justamente o fato de o significado criado por determinado recurso poder falsear a realidade que faz dele um recurso semiótico.

A descrição e a explicação de como, em domínios particulares, os recursos semióticos são usados é, como já foi mencionado, uma das tarefas semióticas apontadas em Jewitt e Oyama (2001). Todavia, o referido trabalho esclarece que a abordagem Semiótica Social da comunicação visual, no que concerne ao método de análise proposto na gramática do design visual, deve ser vista como uma ferramenta para a pesquisa crítica e que seus recursos devem ser utilizados na formulação de questões, aspecto apontado também por Kress e van Leeuwen (1996). Jewitt e Oyama (2001) acrescentam ainda que, na prática, a Semiótica Social Visual deve 
ser aliada a outras teorias, como a teorias sociais, por exemplo, de forma a explicar os resultados das análises descritivas - exigência que igualmente é observada no presente trabalho. Feita essa advertência, Jewitt e Oyama (2001) defendem a efetividade do método no desvelamento de significados. Na seção seguinte, apresentamos estudos que utilizaram o método de análise proposto por Kress e van Leeuwen (1996).

\section{Gramática do design visual: algumas aplicações}

Em 1997, o já mencionado capítulo de Kress, Leite-García e van Leeuwen na coletânea Discourse as structure and process, editada por van Dijk, retoma os pressupostos do método proposto por Kress e van Leeuwen em 1996, para desenvolver modos de compreensão das características dos textos multimodais. O trabalho enfatiza sua afiliação à Semiótica Social, sua concepção da semiose humana, de toda e qualquer forma de construção de significados, como uma atividade social, que produz signos socialmente motivados. $\mathrm{O}$ foco do estudo são os modos semióticos verbal e visual e, no caso deste último, focaliza-se a sintaxe visual. Após uma breve revisão de trabalhos que estudaram o visual em diversas áreas, Kress, Leite-García e van Leeuwen (1997) procedem a uma explicação sucinta das categorias de análise da Semiótica Social do estado de coisas no mundo representado, da Semiótica Social das relações sociais entre observador e imagem e da Semiótica Social do espaço visual, as quais correspondem, respectivamente, às estruturas representacionais, aos significados interativos e à composição.

O capítulo de Kress e van Leeuwen na coletânea Approaches to Media Discourse, de 1998, editada por Bell e Garret, é outro exemplo de trabalhos feitos com base em Kress e van Leeuwen (1996). Tal capítulo parte de categorias propostas na gramática do design visual para apresentar um modelo de descrição a ser utilizado na análise do layout, o qual, segundo Kress e van Leeuwen (1998), vem se tornando o modo de estruturação de textos. O trabalho afirma que os modos semióticos podem se inter-relacionar de várias formas em um texto: significados expressos por meio de imagens e aqueles expressos verbalmente, por exemplo, podem se equivaler, complementar-se ou mesmo se contradizer. Seria preciso, então, "desenvolver modos de análise que possam descrever adequadamente a relação entre o verbal e o visual e possam analisar de forma adequada significados expressos visualmente" (KRESS; VAN LEEUWEN, 1998, p. 187).

Embora tais demandas venham sendo atendidas por trabalhos anteriores desenvolvidos pelos autores, o referido capítulo busca estendê-los e refiná-los, focalizando especificamente a análise do layout. Kress e van Leeuwen (1998) retomam os três sistemas de significação relacionados a esse layout: o valor informacional, a saliência e a moldura. Para fins de 
exemplificação e na análise proposta no final do texto, utiliza-se a primeira página de diferentes jornais de modo a demonstrar a relevância da abordagem "para os estudos críticos da mídia impressa e sua função na sociedade contemporânea" (KRESS; VAN LEEUWEN, 1998, p. 186). Os resultados apontam, em termos gerais, que as primeiras páginas de diferentes jornais “orientam seus leitores para o mundo" (KRESS; VAN LEEUWEN, 1998, p. 216) e relacionam e conferem valores diferentes a gêneros e eventos distintos, o que é feito de forma particular pelos diversos jornais. Além disso, a análise indica ser a mudança um aspecto característico do layout da primeira página.

O estudo de van Leeuwen (2000) é realizado com base na interface entre as abordagens de Kress e van Leeuwen (1996) e de van Leeuwen (1996). Afirmando serem essas abordagens métodos complementares para a análise de como pessoas são representadas, o trabalho aplica algumas de suas categorias à análise de imagens, de modo a identificar estratégias de racismo visual. Van Leeuwen (2000) discute a concepção de Barthes, segundo a qual as imagens, por um lado, simplesmente reproduzem a realidade, estando, portanto, assim como esta, sujeitas à interpretação, e, por outro, reproduzem muitos objetos que trazem associações com sua origem e com valores e ideias a ela relacionados.

Para van Leeuwen (2000), essa concepção vincula o significado ao objeto e o desassocia do ato de significação, no qual tem papel crucial o produtor da imagem, bem como facilita, por exemplo, a negação do racismo comunicado visualmente, uma vez que o atrela aos olhos do observador. Van Leeuwen (2000) afirma, então, que é preciso mostrar que nem sempre as imagens mostram "o que é”, e, se elas fazem apenas alusões às coisas, é preciso explicitar o que é dito implicitamente. $\mathrm{O}$ autor parte de duas questões para analisar como as imagens representam pessoas:

1) como as pessoas são representadas?

2) como as pessoas representadas relacionam-se ao observador?

Para responder à segunda questão, van Leeuwen (2000) baseia-se no trabalho de Kress e van Leeuwen (1996), propondo a análise da distância social, da relação social e da interação social entre o observador e as pessoas representadas. A primeira questão é abordada à luz de categorias propostas para a análise dos modos de representação de atores sociais na linguagem verbal (VAN LEEUWEN, 1996), adaptadas para a análise de imagens. Assim sendo, van Leeuwen (2000) afirma que, no modo semiótico visual, pessoas podem ser incluídas ou excluídas da representação; se incluídas, podem ser representadas como envolvidas ou não em ações e, no primeiro caso, podem figurar como agentes ou pacientes. 
Há também a possibilidade de as pessoas serem referidas de forma específica ou genérica, caso em que pode haver categorização cultural ou biológica. Além disso, as pessoas podem ser representadas individualmente ou em grupos e, neste caso, pode haver homogeneização ou diferenciação. O já mencionado capítulo de Jewitt e Oyama (2001), na coletânea Handbook of Visual Analysis, editada por van Leeuwen e Jewitt, expõe as possíveis contribuições da Semiótica Social da comunicação visual e sumariza o arcabouço descritivo proposto por Kress e van Leeuwen (1996). Para exemplificar como esse arcabouço pode ser utilizado como ferramenta na pesquisa crítica, o trabalho retoma estudos que o fizeram, como os de Jewitt e Kress et al. (2001). Neles, são analisados materiais de promoção da saúde sexual destinados a jovens ingleses, de modo a verificar a representação visual da heterossexualidade masculina. Entre os resultados, destaca-se a constatação de que o material tem uma orientação fortemente heterossexual; simplifica a sexualidade masculina, representando o sexo para o homem como uma atividade física e como uma habilidade ou técnica a ser adquirida; e polariza os papéis de homens e de mulheres, o que enfraquece a ideia de compartilhamento, inclusive no que se refere à responsabilidade pela saúde sexual.

Jewitt e Kress et al. (2001) analisam os significados composicionais e a modalidade em uma espécie de "relatório científico" produzido por dois estudantes de onze anos, após terem feito uma observação ao microscópio. A instrução da professora era a de que, na parte inferior da página, os alunos representassem visualmente o que viram e, na parte superior, relatassem verbalmente o que fizeram. A análise dos textos aponta para o uso de recursos do gênero com interesses distintos para cada criança e para expressões de cientificidade emergindo de forma diferente. Para cada uma, a imagem e a linguagem verbal mediaram a experiência de forma distinta e realizaram aspectos distintos do significado.

Caldas-Coulthard e van Leeuwen (2004), com relação ao aparato da Semiótica Social, analisam os significados de gênero social construídos por brinquedos que representam seres humanos. O trabalho afirma serem os brinquedos artefatos multimodais, podendo ser interpretados como textos e como objetos destinados ao uso. Como textos, eles se situam em discursos diversos e perpetuam ideologias. O significado dos brinquedos emerge, então, do sentido que lhes é atribuído pelos seus produtores e da forma como são usados pelas crianças. Argumenta-se que, sendo um sistema semiótico, os brinquedos possuem o potencial de produzir significados ideacionais, interpessoais e textuais. Caldas-Coulthard e van Leeuwen (2004) analisam, então, o design de brinquedos para meninos e para meninas, as cores usadas em catálogos, além dos significados ideacionais produzidos por meio de textos relacionados aos brinquedos. Os resultados apontam a existência de significados sexistas nas representações de homens e de mulheres em brinquedos destinados a meninos e a meninas. 
No âmbito brasileiro, tem havido um crescente interesse na utilização da Semiótica Social Visual como teoria e método de análise produtivos para a investigação de questões sociais. Da perspectiva da Linguística, cabe destacar o trabalho de Ferraz (2008) como uma abordagem Semiótica Social da comunicação visual. Para fins de exemplificação dessa nova tendência discutiremos, na próxima seção, esse trabalho como parte de nossa tarefa de apontar as novas perspectivas para o texto multimodal na contemporaneidade.

\section{Análise de texto multimodal para o ensino de português para estrangeiros: a Semiótica Social em foco}

Ferraz (2008) busca demonstrar, de maneira prática, como o texto multimodal reflete diversas crenças de seu produtor, ao mesmo tempo em que ressalta a importância de o trabalho ser estruturado por várias semioses para compô-lo. Para tal, apresenta de forma sucinta os modos semióticos envolvidos na composição textual, à luz da Teoria da Semiótica Social, de texto retirado do livro de Grannier e Henriques (2001) para o ensino de português como língua estrangeira, doravante PLE. Nessa proposta, Ferraz toma como ponto de partida o que dizem Kress e van Leeuwen (1996, p. 374) sobre a leitura multimodal:

é impossível interpretar textos prestando atenção somente na língua escrita, pois um texto multimodal deve ser lido em conjunção com todos os outros modos semióticos desse texto.

Ainda na orientação da Semiótica Social, esses linguistas destacam algumas das categorias para a análise de imagens, abordando especificamente a categoria dos Participantes Representados e a do Processo Narrativo Reacional. A categoria dos Participantes divide-se em dois tipos: participantes representados e interativos. Nessa análise, Ferraz (2008) trabalha apenas com os participantes representados, os quais são os objetos da comunicação (pessoas, lugares, coisas) sendo, portanto, os participantes sobre os quais se está falando, escrevendo ou produzindo imagens. A categoria do Processo Narrativo ocorre quando participantes são conectados por um vetor, sendo, dessa forma, representados como "fazendo algo para o outro". Os processos narrativos diferenciam-se de acordo com o tipo de vetor, com o número e com os tipos de participantes envolvidos. A autora enfoca o Processo Narrativo Reacional, que se constitui quando o vetor é formado pela linha dos olhos, pela direção do olhar de um ou mais participantes representados. O participante do qual parte o vetor do olhar é chamado de reacter e deve ser necessariamente humano ou animal. 
Agora, observemos o seguinte texto analisado por Ferraz (2008):

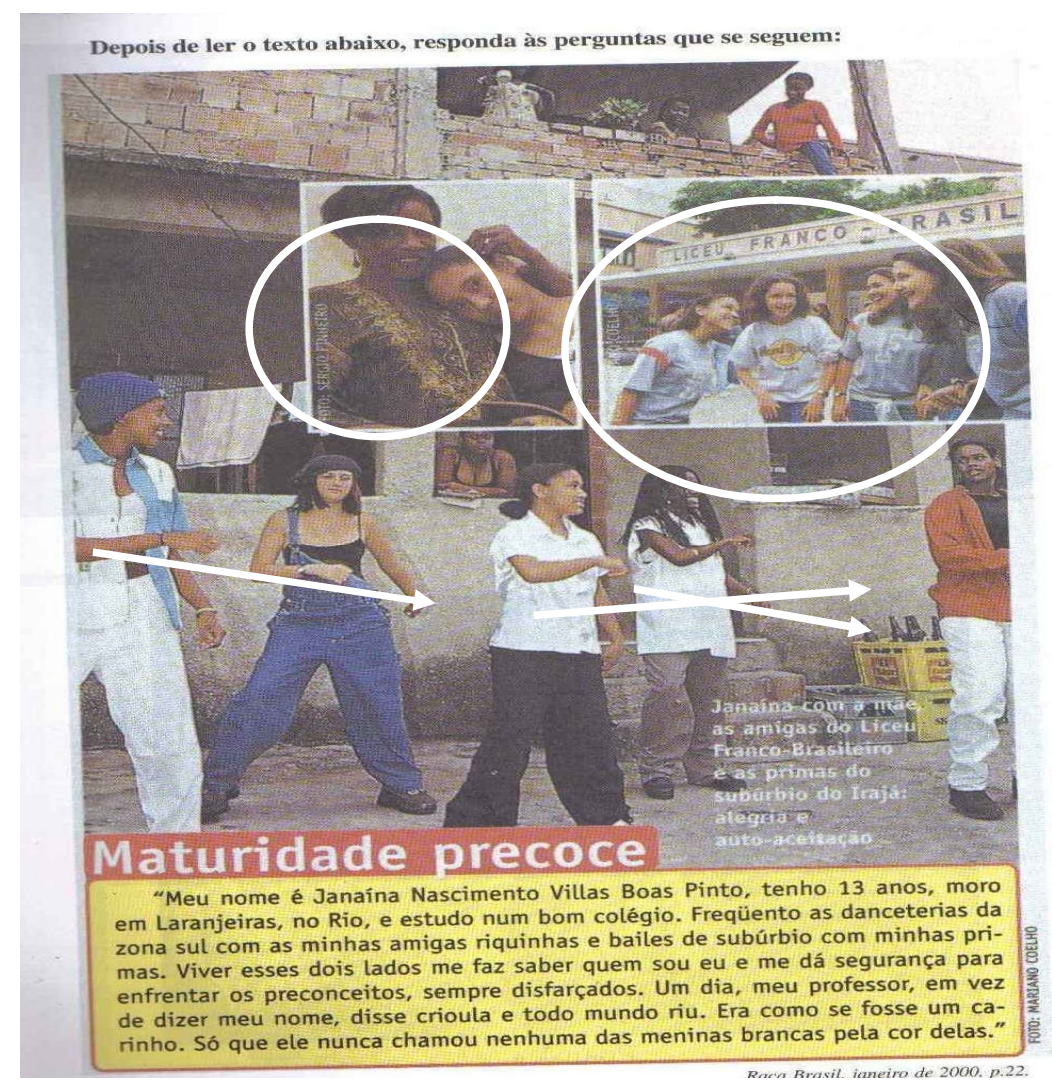

Figura 7 - Texto multimodal extraído de Grannier e Henriques (2001)

Por meio da análise dos elementos que compõe a imagem, a autora afirma ser possível verificar os seguintes pontos vislumbrados pela Teoria da Semiótica Social:

a) categoria dos participantes representados: meninas dançando, conversando e elementos que representam, tanto o subúrbio a que a autora se refere (o sobrado malacabado), quanto a boa escola (com boa estrutura, paredes pintadas).

Neste caso, observa-se que a imagem representa cenas reais e cotidianas da menina, participante representado, mas a escolha dos participantes e o modo como eles estão representados não são neutros. Ferraz verifica que o produtor do texto quis enfatizar a diferença dos grupos não só pela modalidade escrita como também pela gramática visual. Isso pode ser visto pela maneira como as fotografias estão dispostas e pelo fundo contrastante de ambas, que revelam construções e condições diferentes.

b) categoria do processo narrativo reacional: as setas mostram que as participantes (reacters) estão interagindo entre si: tanto na dança, quanto na conversa, o olhar é direcionado para outro agente. 
Ferraz (2008) alerta para o fato de os aspectos ideológicos que permeiam os textos multimodais poderem ser naturalizados no discurso do aluno caso o professor não realize um trabalho adequado com esse tipo de texto. A autora ressalta ainda que cabe ao docente apresentar aos alunos estrangeiros uma perspectiva sobre a realidade social de falantes nativos da línguaalvo, no caso, os brasileiros. Esses significados são apresentados e trabalhados em livros didáticos que auxiliam os alunos na formação de crenças e de valores. Por esse motivo, o professor de língua estrangeira deve ter consciência da importância do trabalho estruturado e sistemático com textos multimodais e, assim, evitar o reforço de determinados estereótipos sobre a cultura brasileira por parte dos alunos, o que nos permite vislumbrar como a multimodalidade pode, de fato, ser uma alternativa para repensar as práticas sociais nas quais textos de natureza diversa estejam envolvidos.

Terminada a tarefa de apresentar uma pesquisa guiada pela proposta analítica da Semiótica Social, no contexto acadêmico brasileiro, acreditamos ter apontado, por meio de exemplos multimodais, um caminho definitivo para a realização de trabalhos que investiguem processos discursivos nos contextos mais diversos. Passamos, na próxima seção, às nossas primeiras conclusões.

\section{Primeiras conclusões}

Ao levarmos em conta, mais uma vez, a Teoria da Semiótica Social (Kress e Van Leeuwen), que defende serem os participantes em posição de poder (produtores dos signos) os que levam os outros participantes (leitores) a um maior esforço de interpretação, diferenciando a noção de entendimento do receptor da mensagem, temos em mente que dar lugar à imagem no âmbito dos estudos linguísticos é um caminho que auxilia a desvelar os fenômenos da linguagem.

A verdade é que os sujeitos do discurso, sejam crianças, sejam adultos, devem estar preparados para um mundo multimodal, povoado de imagens e de sons, para poderem desvendar mensagens. Quem não souber ler esse tipo de discurso estará em séria desvantagem, pois facilmente poderá ser manipulado por toda a sorte de informação que use esses recursos multimodais. A resistência efetiva é saber lidar criticamente com a natureza desse tipo de discurso.

Os textos aqui analisados revelaram aspectos ideológicos da construção multimodal e o interesse dos produtores de textos guiados pelas necessidades sociais. O que temos de fazer com a emergente força da imagem no momento atual de nossa história é voltarmo-nos para formas de investigação como as aqui descritas: com enfoque nas diversas semioses envolvidas na produção 
de sentidos como um meio legítimo de método analítico, afinal, a efetiva e completa pesquisa científica deve passar pelo papel de desconstrutora da ação alienante da imagem para uma avaliação crítica de tudo o que vemos. Aprender a lidar com o excesso de informações do mundo mediado das sociedades modernas é portentoso recurso de pesquisa e de construção de conhecimento.

Por fim, a discussão do tema não se esgota aqui e poderia ser ainda amplamente abordada, mas, para os propósitos deste artigo, entendemos que chamamos a atenção para o fenômeno da multimodalidade e acreditamos que a profundidade, a relevância e a abrangência do assunto provoquem o debate entre outros pesquisadores no cenário brasileiro de estudos da linguagem.

\section{Referências}

BALDRY, A.; THIBAULT, P. J. Multimodal transcription and text analysis: a multimedia toolkit and coursebook with associated on-line course. Equinox: London, 2006.

CALDAS-COULTHARD, C. R.; VAN LEEUWEN, T. Discurso crítico e gênero no mundo infantil: brinquedos e a representação de atores sociais. Linguagem em (Dis)curso, Tubarão, v. 4, n. esp., 2004.

FAIRCLOUCH, N. Discurso e mudança social. trad. Izabel Magalhães. Brasília: UnB 2001.

FAIRCLOUGH, N. Genres and generic structure. In: ___. Analysing discourse: textual analysis for social research. London; New York: Routledge, 2003.

FERRAZ, J. A. A formação identitária do brasileiro: um enfoque multimodal. 2005. 105 p. Dissertação (mestrado) Universidade de Brasília. (mimeo).

. Gêneros Multimodais: novos caminhos discursivos. In: Anais do VIII ENIL. Humanitas: São Paulo, 2008. Disponível em: http://www.fflch.usp.br/dlcv/enil/index.html

. A multimodalidade e a formação dos sentidos em português como segunda língua. In: Olhares em análise de discurso crítica. Vieira: Brasília, 2008. Disponível em: www.cepadic.com

HALLIDAY, M. A. K.; MATTHIESSEN, C. An introduction to functional grammar. 3 ed. London: Edward Arnold, 2004.

HALLIDAY, M. A. K. Language as social semiotic. London: Edward Arnold, 1978.

. An introduction to functional grammar. London: Edward Arnold, 1985.

. An introduction to functional grammar. 2 ed. London: Edward Arnold, 1994.

HENRIQUES, E. R. \& GRANNIER, D. M. (2001). Interagindo em Português: textos e visões do Brasil. Brasília: Thesaurus. HODGE, R.; KRESS, G. Social Semiotics. Ithaca, New York: Cornell University Press, 1988.

JEWITT, C.; OYAMA, R. Visual meaning: a Social Semiotic approach. In: VAN LEEUWEN, T.; JEWITT, C. Handbook of visual analysis. London, Thousand Oaks, New Delhi: Sage Publications, 2001.

KRESS, G. Literacy in the new media age. London and New York: Routledge, 2003.

KRESS, G.; VAN LEEUWEN, T.. Representation and interaction: designing the position of the viewer. In: JAWORSKI, A.; COUPLAND, N. (Eds.) The discourse reader. London: Routledge, 1999.

KRESS, G.; LEITE-GARCIA, R.; VAN LEEUWEN, T. Discourse Semiotics. In: van DIJK, T. Discourse as structure and process. London; Thousand Oaks; New Delhi: Sage Publications, 1997.

KRESS, G.; VAN LEEUWEN, T. Reading images: the grammar of visual design. London, New York: Routledge, 1996.

. Front pages: (the critical) analysis of newspaper layout. In: BELL, A.; GARRETT, P.(Eds.). Approaches to media discourse. Oxford: Blackwell, 1998.

Multimodal discourse: the modes and media of contemporary communication. London: Arnold, 2001.

VAN LEEUWEN, T. The representation of social actors. In: CALDAS-COULTHARD, C. R.; COUTHARD, M. (Eds.). Texts and practices: readings in Critical Discourse Analysis. London e New York: Routledge, 1996.

VAN LEEUWEN, T. Semiotics and iconography. In: VAN LEEUWEN, T.; JEWITT, C. (Eds.) Handbook of visual analysis. London, Thousand Oaks, New Delhi: Sage Publications, 2001.

. Style. In: VAN LEEUWEN, T. Introducing social semiotics. London; New York: Routledge, 2005.

VIEIRA, J.A; FERRAZ, J.A; ROCHA, H.; BOU MAROUN, C. Reflexões sobre a língua portuguesa: uma abordagem multimodal. Petrópolis: Vozes, 2007. 